\title{
Kinetic Study of the Leaching of Iraqi Akashat Phosphate Ore Using Lactic Acid
}

\author{
Mohammed Y. Eisa* $\quad$ Basma A. Abdulmajeed** $\quad$ C. K. Haweel*** \\ * Department of Biochemical Engineering/AlKhwarizmi College of Engineering/University of Baghdad/ Iraq \\ **,*** Department of Chemical Engineering/College of Engineering/ University of Baghdad/ Iraq \\ *Email: $\underline{\text { mohammedyeisa@yahoo.com }}$
}

(Received 18 July 2017; accepted 24 August 2017)

https://doi.org/10.22153/kej.2018.08.006

\begin{abstract}
In the present work, a kinetic study was performed to the extraction of phosphate from Iraqi Akashat phosphate ore using organic acid. Leaching was studied using lactic acid for the separation of calcareous materials (mainly calcite). Reaction conditions were $2 \%$ by weight acid concentration and $5 \mathrm{ml} / \mathrm{gm}$ of acid volume to ore weight ratio. Reaction time was taken in the range 2 to 30 minutes (step 2 minutes) to determine the reaction rate constant $\mathrm{k}$ based on the change in calcite concentration. To determine value of activation energy when reaction temperature is varied from 25 to $65^{\circ} \mathrm{C}$, another investigation was accomplished. Through the kinetic data, it was found that selective leaching was controlled by surface chemical reaction. The study showed that the reaction kinetics was specifically described by the shrinking core model (SCM). Regression analyses gave values of activation energy $\left(E_{a}\right)$ and Arrhenius constant $\left(k_{o}\right)$ as $40.108 \mathrm{KJ} / \mathrm{mole}$ and $\left(2.256 \times 10^{3} \mathrm{sec}^{-1}\right)$ respectively.
\end{abstract}

Keywords: Phosphate Ore, Organic Acid Leaching, Lactic Acid, Reaction Kinetics.

\section{Introduction}

In the mid of nineteenth century, phosphate industry was established through the production of phosphatic fertilizer. Gradually, higher purity and more economical phosphates manufactured from elemental phosphorus became available. So the diversity and volume of applications of this product was dramatically preceded. (KirkOthmer,1998).

The main sources of phosphate in the world are phosphate rocks. Mining of these ores provides the required amounts for fertilizers and the other industrial chemicals by chemical processing and beneficiation. These natural resources are neither non-renewable nor substitutable.

Approximately $75-80 \%$ of the phosphate ores are classified as sedimentary, $15-20 \%$ are igneous and only $1-2 \%$ are from biological origin. (Straaten, 2002; Guimarães et al., 2005).
Approximately, there are 200 known types of minerals contain more than $1 \% \mathrm{P}_{2} \mathrm{O}_{5}$. Apatite is the most important ore used for the phosphate and phosphoric acid industry (Becker, 1983; Gremillion and McClellan, 1975).

In Iraq, the most important formation is Akashat phosphate which contains approximately $21-22 \%$ of phosphorus pentoxide. This ratio can be increased to about $25 \%$ using simple physical methods. These deposits appear in sedimentary layers accompanied with limestone and clay. Francolite Apatite $\mathrm{Ca}_{10}\left(\mathrm{PO}_{4}\right)_{6} \mathrm{~F}_{2}$ is the main metal component of these ores associated with calcite (Shirqi and Tawfiq, 2010).

Phosphate, produced by mining, contains other minerals. Only apatite mineral is needed for phosphoric acid manufacture. The other minerals must to be removed by beneficiation. First the raw phosphate is washed by water to remove the soluble impurities. It is necessary to remove the carbonate and siliceous impurities to avoid problems in the manufacture of phosphoric acid. 
The siliceous impurities consist of tiny particles, which cause problems in the filtration stage. The removal of carbonate content is so essential before the digestion of the phosphate rock in the inorganic acid. In contrast, excessive foaming occurs due to the formation of carbon dioxide in this stage (Rao et al., 1992; Sluis, 1987).

Usually, the $\mathrm{P}_{2} \mathrm{O}_{5}$ content in the marketable phosphate ore is about $28-36 \%$ and $35-39 \%$ for the sedimentary and igneous types respectively. In order to be economical, carbonate content should not exceed $8 \%$ in phosphate ores (Gharabaghi et al., 2009). In the fertilizer industry, phosphate ores must have more than $30 \% \quad \mathrm{P}_{2} \mathrm{O}_{5}$ content. Depending on the particle size of phosphate, mineral impurities content and other specifications, effective beneficiation is achieved using different approaches, (Heidarpour, 2009).

In addition, the presence of carbonates in the phosphate rocks requires more sulfuric acid during the manufacture of superphosphates and phosphoric acid using the wet process. In the other hand, the formed carbon dioxide through addition of acid causes the production of smaller size crystals of gypsum that may blind the phosphor gypsum filters leading to production of a low quality phosphoric acid (Malash, 2005).

A worldwide problem is the beneficiation of sedimentary phosphate ores containing carbonate impurities and there is no adequate method to treat such ores on an industrial scale. However, calcination is utilized (Abouzeid, 2008).

Calcination use is limited in areas where low cost energy and water resources are abundant. As any other method with a negative attitude, the calcined phosphate has a lower quality concerning the reactivity and surface properties (Ozer, 2003).

Chemical dissolution of carbonate minerals (calcite and dolomite) from calcareous phosphate ores, without calcination, using organic acids also proved capable of upgrading the calcareous phosphate ores on the laboratory scale. With regard to the problems with sedimentary phosphate ores, acid leaching is a promising method that can be applied to treat the calcareous phosphate ores and more attention being given to leaching methods. Since nearly $80 \%$ of the world's phosphate resources are calcareous ores (Gharabaghi et al., 2009).

Studies on the separation of carbonate ores by organic acids are limited. However, the results showed the effectiveness of acetic acid, lactic acid, formic acid and succinic acid for leaching of calcareous phosphate ores. Many of the problems occurred through the production of phosphoric acid and superphosphates are treated using this leaching technique. Both magnesium and calcium carbonates are removed efficiently using this approach with small time of reaction and so minimum destructive effects (Bilgic 2002).

For instance, equation (1) shows the reaction of lactic acid with carbonate minerals for dissolution (Gharabaghi et al., 2010):

$\mathrm{CaCO}_{3(\mathrm{~s})}+\mathrm{CH}_{3} \mathrm{CH}(\mathrm{OH}) \mathrm{COOH}_{(\mathrm{aq})}=$

$\mathrm{Ca}\left(\mathrm{CH}_{3} \mathrm{CH}(\mathrm{OH}) \mathrm{COO}\right)_{2(\mathrm{aq})}+\mathrm{CO}_{2(\mathrm{aq})}+\mathrm{H}_{2} \mathrm{O}_{(\mathrm{l})} \ldots$ (1)

Due to the removal of $\mathrm{CO}_{2}$ produced during the reaction, this process may be considered as an irreversible.

In order to understand the process of selective leaching, the simplest mechanism for the reaction can be shown as follows (Zafar and Ashraf, 2007):

$\mathrm{MCO}_{3(\mathrm{~s})}+2 \mathrm{HX}_{(\mathrm{aq})} \rightarrow \mathrm{MX}_{2(\mathrm{aq})}+\mathrm{CO}_{2(\mathrm{~g})}+\mathrm{H}_{2} \mathrm{O}_{(\mathrm{l})} \ldots(2)$ $\mathrm{M}_{3}\left(\mathrm{PO}_{4}\right)_{2(\mathrm{~s})}+6 \mathrm{HX}_{(\mathrm{aq})} \rightarrow 3 \mathrm{MX}_{2(\mathrm{aq})}+$

$2 \mathrm{H}_{3} \mathrm{PO}_{4(\mathrm{aq})}$

where:

$\mathrm{M}=\mathrm{Ca}^{+2}$ and/or $\mathrm{Mg}^{+2}$, and $\mathrm{X}=\mathrm{CH}_{3} \mathrm{CH}(\mathrm{OH}) \mathrm{COO}^{-}$ (lactate).

To avoid the dissolution of phosphate mineral by the organic acid, reaction (3) should not takes place while reaction (2) proceeds to completion. Reactions of formic and succinic acid are similar to lactic and acetic acid. In this case, succinate and formate can be substituted with $\mathrm{X}$ in Equations (1) and (2) taking into account the stoicheometric consideration (Gharabaghi et al., 2010).

In a previous work (Haweel C.K. et al., 2013), leaching process was studied using two organic acids (acetic acid and lactic acid) to beneficiate phosphate from Iraqi Akashat phosphate ore. The obtained experimental data of X-Ray Diffraction (XRD) and Fourier Transform Infra Red (FTIR) showed that lactic acid is more efficient than acetic acid as shown in figures (1) to (4).

Comparing the spectrum of Figures (1) and (2) show a decrease in calcite content at $2 \theta=29^{\circ}$ and an increase in phosphate content at $2 \theta=32^{\circ}$. The same conclusion is found in Figures (3) and (4) where the FTIR absorbencies of calcite is decreased near $1430 \mathrm{~cm}^{-1}$ while phosphate absorbencies increased near $1050 \mathrm{~cm}^{-1}$ wave number to assure the XRD results. 


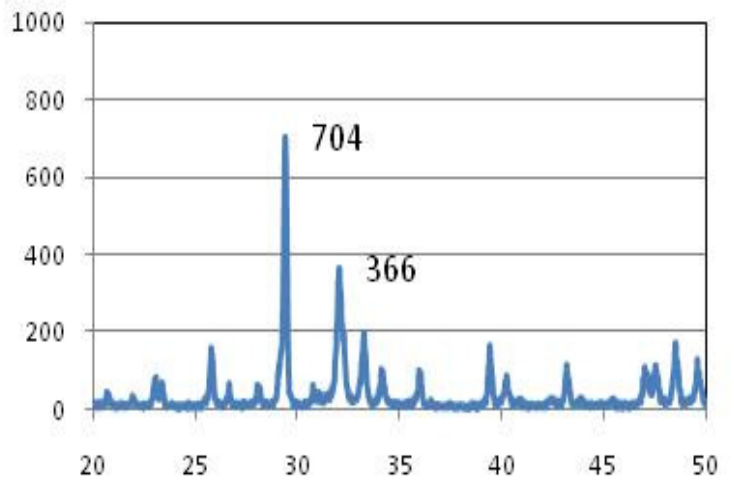

Fig. 1. XRD Spectra of raw Akashat phosphate Ore size 300 micron.

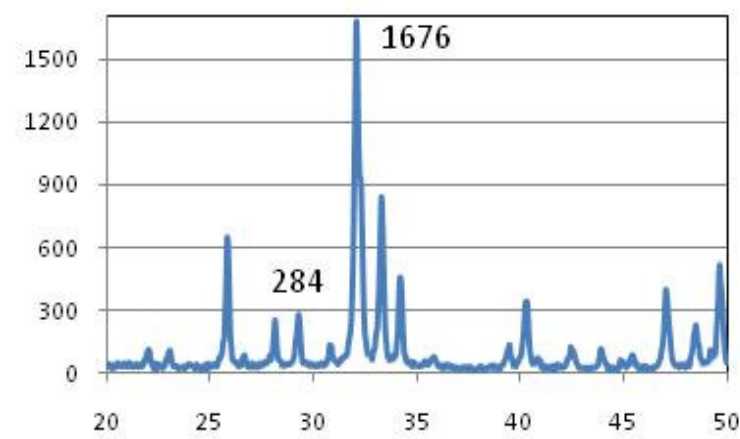

Fig. 2. XRD Spectra of beneficiated Akashat phosphate ore size 300 micron using lactic acid leaching.

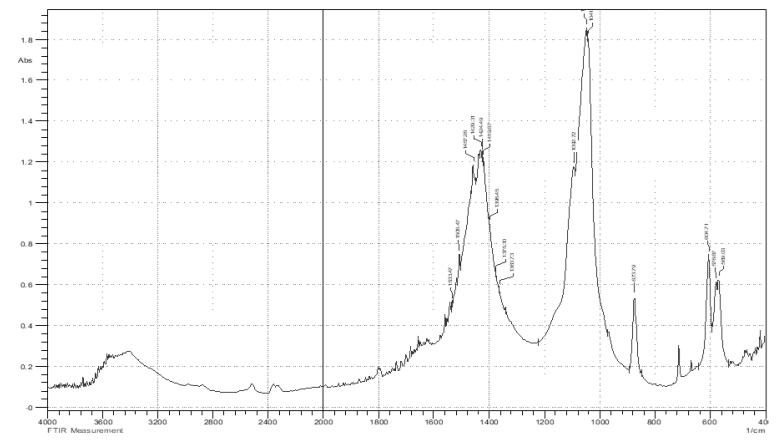

Fig. 3. FTIR Spectra of raw Akashat phosphate Ore size 300 micron.

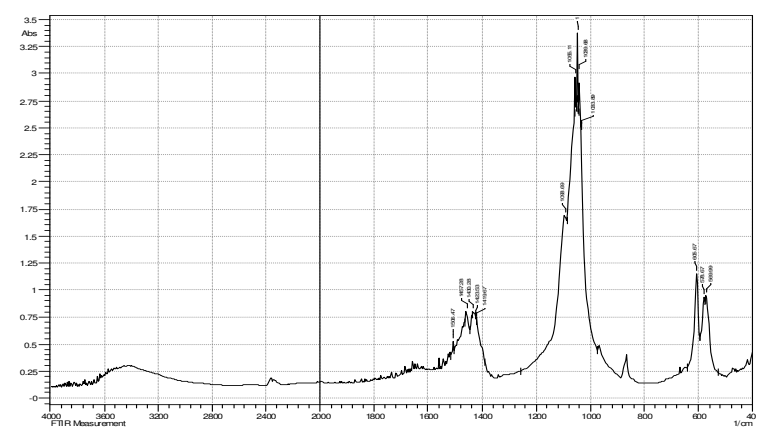

Fig.4. FTIR Spectra of beneficiated Akashat phosphate ore size $\mathbf{3 0 0}$ micron using lactic acid leaching.
In relating to the volume of acid to ore weight ratio, the investigation shows that reducing this ratio to $5 \mathrm{ml} / \mathrm{gm}$ enhances the purity of apatite at the optimum acid concentration (Haweel, C.K. et. al., 2013).

\section{Kinetics of Chemical Reaction}

In the type of heterogeneous reactions, where a fluid is in contact with a solid, reaction takes place and gives product. Three cases fluid, solid or fluid and solid mixture products are expected.

As shown in Figure (5), when the solid particles contain large amounts of impurities they remain unchanged in size during reaction as a nonflaking ash. In the other hand, when a flaking ash is formed or when pure solid reactant is used, the reaction particles shrink in size during reaction.

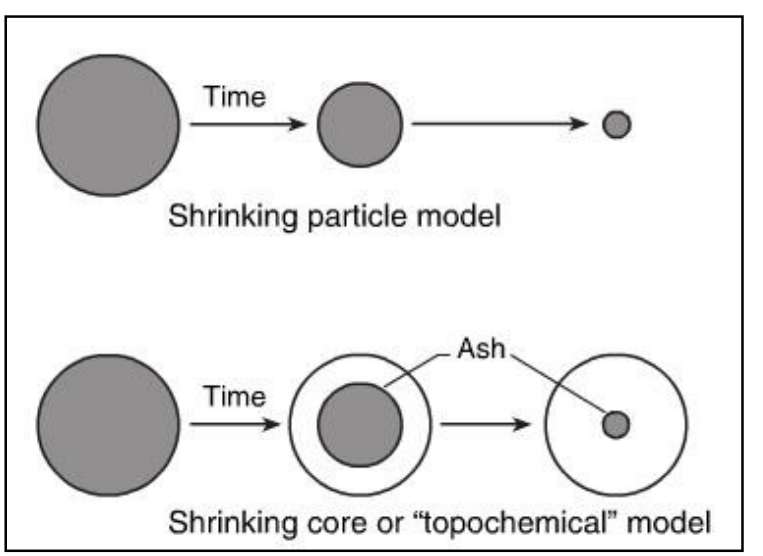

Fig. 5. Different sorts of behavior of reacting solid particle (Cussler, 2007).

Regarding mass transfer and reaction kinetics a number of models are available for the dissolution of solid particles with the surrounding fluid (Hem, 1993). It is necessary to be understood that every conceptual model for the progress of reaction comes with its mathematical model and rate equation. If a model corresponds closely to what really occurs, then its rate expression will preciously fit the suitable kinetics; if a model differs from reality, then its kinetic models will be useless.

For noncatalytic reaction of particles with surrounding fluid, the progressive conversion model (PCM) and the unreacted core (shrinking core) model (SCM) may be considered.

When a fluid reacts with the solid particle at a constant rate, the progressive conversion model 
(PCM) may be fit. Thus, solid reactant is converted continuously throughout the particle and progressively.

In the shrinking core model (SCM), it is found that reaction occurs first at the particle surface. The reaction part then moves into the solid, leaving completely converted material and the ash. Thus, continuously, an unreacted core of material exists shrinking in size as the reaction proceeds. However, the unreacted core model seems to reasonably represent reality more closely in most cases than does the progressive conversion model (Octave, 1999).

The shrinking core model of unchanging size particle was first developed by (Yagi, 1955). Five steps were suggested to be occurred during reaction:

1. Diffusion of fluid reactant through the outer film to the surface of the solid particle.

2. Penetration through the ash to the inner unreacted core.

3. Chemical reaction of fluid with solid at the reaction surface.

4. Fluid products diffusion through the ash to the solid outer surface.

5. Fluid products diffusion through the gas film returning to the bulk of fluid.

In many cases some of these steps do not exist. In such cases it may be considered that the lowest step to be rate-controlling (Kunii, 1991). In this treatment, the rate equations for spherical particles are shown below:

For film diffusion control:

$\frac{\mathrm{t}}{\tau}=1-\left(\frac{\mathrm{r}_{\mathrm{c}}}{\mathrm{R}}\right)^{3}=\mathrm{X}_{\mathrm{B}}$

For chemically controlled process:

$\frac{\mathrm{t}}{\tau}=1-\frac{\mathrm{r}_{\mathrm{c}}}{\mathrm{R}}=1-\left(1-\mathrm{X}_{\mathrm{B}}\right)^{1 / 3}$

For product layer diffusion control:

$\frac{\mathrm{t}}{\tau}=1-3\left(1-\mathrm{X}_{\mathrm{B}}\right)^{2 / 3}+2\left(1-\mathrm{X}_{\mathrm{B}}\right)$

Where:

$\boldsymbol{\tau}$ is the time for complete conversion of a particle. $\mathbf{X}_{\mathbf{A}}$ is the conversion of calcareous material after time $\mathbf{t}$.

$\mathbf{R}$ is the radius of the particle.

$\mathbf{r}_{\mathbf{c}}$ is the radius of the particle core.

These rate expressions were used to test the validity and best fit to the experimental data as shown in the next sections (Octave, 1999).

An investigation is to be conducted to specify the type of kinetic model which fit to the selective leaching of Iraqi Akashat phosphate ore using lactic acid and to calculate Arrhenius equation parameters.

\section{Experimental Work}

In order to specify the kinetic behavior of the reactants and the rate of reaction control step, a set of experiments was performed to study the change in fractional conversion of calcite $\left(\mathrm{X}_{\mathrm{A}}\right)$ with time.

For selective leaching studies, $(-0.125+0.30$ $\mathrm{mm}$ ) size fractions of Akashat phosphate ore were used as the source of phosphate. Sample was added to a well mixed three necked funnel glass batch reactor of $(500 \mathrm{ml})$ size, equipped on a magnetic stirrer having a controller unit.

A known amount of lactic acid $10 \%$ by weight concentration with the liquid to solid $(\mathrm{L} / \mathrm{S}=5)$ volume ratio was slowly pipetted into the reactor vessel containing $5.0 \mathrm{~g}$ of the sample for a specific time each run according to the set of experiments shown in table 1.

Table 1,

LOI data of phosphate ore leaching using Lactic acid at the operating conditions $(10 \mathrm{wt} \%, \mathrm{~L} / \mathrm{S}=5)$

\begin{tabular}{lllll}
\hline No. & $\begin{array}{l}\text { Time } \\
(\mathbf{s e c} .)\end{array}$ & (LOI) $\%$ & $\begin{array}{c}\text { Calcite } \\
\text { Wt.\% }\end{array}$ & $\begin{array}{c}\text { Conversion } \\
\left(\mathbf{X}_{\mathbf{A}}\right)\end{array}$ \\
\hline 1 & 0 & 21.6172 & 49.13 & 0 \\
2 & 120 & 19.1884 & 43.61 & 0.11 \\
3 & 240 & 17.3558 & 39.445 & 0.195 \\
4 & 360 & 15.3076 & 34.79 & 0.29 \\
5 & 480 & 13.4103 & 30.478 & 0.378 \\
6 & 600 & 12.1383 & 27.587 & 0.437 \\
7 & 720 & 10.5644 & 24.01 & 0.51 \\
8 & 840 & 9.2708 & 21.07 & 0.57 \\
9 & 960 & 7.9772 & 18.13 & 0.63 \\
10 & 1080 & 6.8345 & 15.533 & 0.683 \\
11 & 1200 & 6.1446 & 13.965 & 0.715 \\
12 & 1320 & 5.6056 & 12.74 & 0.74 \\
13 & 1440 & 4.9588 & 11.27 & 0.77 \\
14 & 1560 & 4.4629 & 10.143 & 0.793 \\
15 & 1680 & 3.9670 & 9.016 & 0.816 \\
16 & 1800 & 3.9670 & 9.016 & 0.816 \\
\hline
\end{tabular}

Acid concentration is calibrated using $\mathrm{pH}$ meter. Temperature for all experiments fixed under control $\left(30^{\circ} \mathrm{C}\right)$. Mixing speed at $300 \mathrm{rpm}$ to ensure steady dispersion of particles in the liquid phase. Reaction time was taken in the range 2 to 30 minutes (step 2 minutes) to determine the rate of reaction constant $\mathrm{k}$ based on the change in calcite concentration.

At the end of each run, mixing was immediately stopped to end the reaction. The leaching slurry is then separated using vacuum filtration.

The resulting filtrates were then dried, weighed and analyzed by loss on ignition (LOI) by 
calcination at $900^{\circ} \mathrm{C}$ using muffle furnace (Nabertherm-N20/H-West Germany) to investigate the change in reactant (calcite) concentration with time as shown in table 1.

$L O I \%=\frac{W_{o}-W_{i}}{W_{o}} \times 100 \%$

Where:

$\mathrm{W}_{\mathrm{o}}=$ initial weight of phosphate (g) before calcination

$\mathrm{W}_{\mathrm{i}}=$ final weight of phosphate after leaching $(\mathrm{g})$ after calcination

The difference in weight by calcination of beneficiated phosphate ore gives the calcite content which decreased with time according to the observed data of table 1 .

\section{Results and Discussion}

After the reaction completion, it was found that the final particles are hard, firm and unchanging in size. Therefore the shrinking particle model with changing size was not properly working in the present case. Keeping in view that the shrinking core model (SCM) may be considered to appropriately work regarding this dissolution behavior.

In order to specify the rate controlling step of the specified model, Figure 7 is plotted to show the effect of reaction time on the fractional conversion of reactant based on data of Table 2 . Three cases of reaction rate control were plotted supported by statistical analysis to test the validity of the experimental data using Equations 4, 5 and 6 for the fluid layer diffusion, ash layer diffusion and chemical reaction control respectively. Values of correlation coefficients determination for these rate expressions were compared.

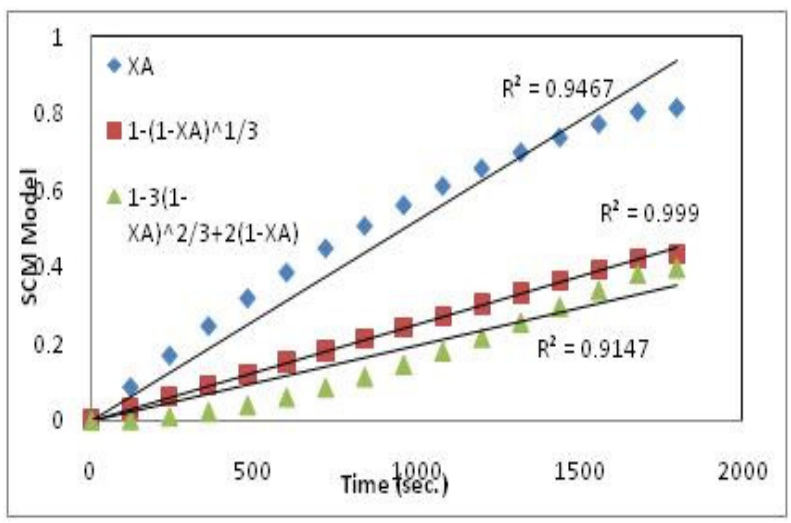

Fig. 6. Effect of reaction time on $X_{A}, 1-\left(1-X_{A}\right)^{1 / 3}$, 1$3\left(1-X_{A}\right)^{2 / 3}+2\left(1-X_{A}\right)$
From the regression analysis and Figure 6, it was found that just one of the plots gives a straight line which is fit to the model of chemical reaction control, i.e. that the best value of correlation coefficient promising the rate expression was for chemical reaction control and its value was calculated as 0.999 . So, it was found that this reaction was controlled by chemical reaction according to the expression $\left[1-(1-\mathrm{XA})^{1 / 3}=\mathrm{Kt}\right]$ of Equation 5. Value of reaction rate constant in return to this regression is $\left(2.51 \times 10^{-4} \mathrm{sec}^{-1}\right)$.

In a relevant study by (Zafar and Ashraf, 2007), the kinetic data of leaching of another type of calcareous phosphate rock in lactic acid was analyzed by graphical and statistical methods, showed that the leaching was controlled by chemical reaction. The obtained results by the present work also confirm other earlier reported results (Economou and Vaimakis, 1997; Fairchild et al., 1999).

Table 2,

Kinetic data of phosphate ore leaching using Lactic acid at the operating conditions $(10 \mathrm{wt} \%, \mathrm{~L} / \mathrm{S}=5)$

\begin{tabular}{|c|c|c|c|c|}
\hline No & $\begin{array}{l}\text { Time } \\
\text { (sec.) }\end{array}$ & $\begin{array}{c}\text { Conv. } \\
\left(\mathbf{X}_{\mathbf{A}}\right)\end{array}$ & $1-\left(1-X_{A}\right)^{1 / 3}$ & $1-3\left(1-X_{A}\right)^{2 / 3}+2\left(1-X_{A}\right)$ \\
\hline 1 & 0 & 0 & 0 & 0 \\
\hline 2 & 120 & 0.11 & 0.0381 & 0.0042 \\
\hline 3 & 240 & 0.195 & 0.0698 & 0.0139 \\
\hline 4 & 360 & 0.29 & 0.1079 & 0.0324 \\
\hline 5 & 480 & 0.378 & 0.1464 & 0.0580 \\
\hline 6 & 600 & 0.437 & 0.1743 & 0.0805 \\
\hline 7 & 720 & 0.51 & 0.2116 & 0.1154 \\
\hline 8 & 840 & 0.57 & 0.2452 & 0.1509 \\
\hline 9 & 960 & 0.63 & 0.2821 & 0.1938 \\
\hline 10 & 1080 & 0.683 & 0.3182 & 0.2393 \\
\hline 11 & 1200 & 0.715 & 0.3419 & 0.2708 \\
\hline 12 & 1320 & 0.74 & 0.3617 & 0.2979 \\
\hline 13 & 1440 & 0.77 & 0.3873 & 0.3338 \\
\hline 14 & 1560 & 0.793 & 0.4085 & 0.3642 \\
\hline 15 & 1680 & 0.816 & 0.4312 & 0.3975 \\
\hline 16 & 1800 & 0.816 & 0.4312 & 0.3975 \\
\hline
\end{tabular}

\section{Activation Energy}

Activation energy can be calculated using Arrhenius equation (8). A set of experiments relates temperature in the range $\left(25-65^{\circ} \mathrm{C}\right)$ with the reactant conversion based on the loss on ignition test LOI at the best reaction conditions using lactic acid were applied, as shown in Table 3.

A plot is drown according to the data calculations shown in Table 3 of $\ln \mathrm{k}$ versus 1/T in order to correlate values of Arrhenius Equation parameters. A straight line was resulted with a slop of $(-\mathrm{Ea} / \mathrm{R})$ and an intercept of $\left(\ln \mathrm{k}_{\mathrm{o}}\right)$ as shown in Figure 7. 
From this figure and a regression analysis with correlation coefficient (0.9747), value of activation energy $\left(E_{a}\right)$ was calculated as 40.108 $\mathrm{KJ} / \mathrm{mole}$ and Arrhenius constant $\left(K_{o}\right)$ was $\left(2.256 \times 10^{3} \mathrm{sec}^{-1}\right)$.

Through the obtained results, it was found that selective leaching of Akashat phosphate ore using lactic acid was controlled by surface chemical reaction. So the shrinking core model Equation 8 can be used to describe the reaction kinetics:

$$
1-\left(1-X_{A}\right)^{1 / 3}=\frac{b K^{\prime \prime} C_{A}}{\rho_{B} R} t=K_{r} t=1.354 \times
$$$$
10^{3} \exp (-40108 / R T) \cdot t
$$

Parameters of Equation 8 are detailed below: $b$ is the stoichiometric ratio of the solid reactant $\mathrm{B}$ $K^{\prime \prime}$ is the $1^{\text {st }}$ order rate constant for the surface reaction

$C_{A}$ is the concentration of the fluid reactant (mol/lit)A

$\rho_{B}$ is the molar density of solid reactant $\left(\mathrm{mol} / \mathrm{m}^{3}\right)$

Table 3,

Experimental Data of Arrhenius Equation Parameters

\begin{tabular}{llllll}
\hline No & $\mathbf{T}^{\mathbf{0}} \mathbf{K}$ & $\mathbf{X}_{\mathbf{A}}$ & $\begin{array}{l}\mathbf{K}=(\mathbf{1}-(\mathbf{1}- \\
\left.\left.\mathbf{X}_{\mathbf{A}}\right)^{\mathbf{1 / 3}}\right) \mathbf{t}\end{array}$ & $\mathbf{l n} \mathbf{K}$ & $\mathbf{1 / T}$ \\
\hline 1 & 298 & 0.806 & 0.4216 & -8.3592 & 0.00335 \\
2 & 308 & 0.847 & 0.4655 & -8.0370 & 0.00325 \\
3 & 318 & 0.86 & 0.4807 & -7.4658 & 0.00314 \\
4 & 328 & 0.926 & 0.5802 & -7.1237 & 0.00305 \\
5 & 338 & 0.932 & 0.5918 & -6.4106 & 0.00296 \\
\hline
\end{tabular}

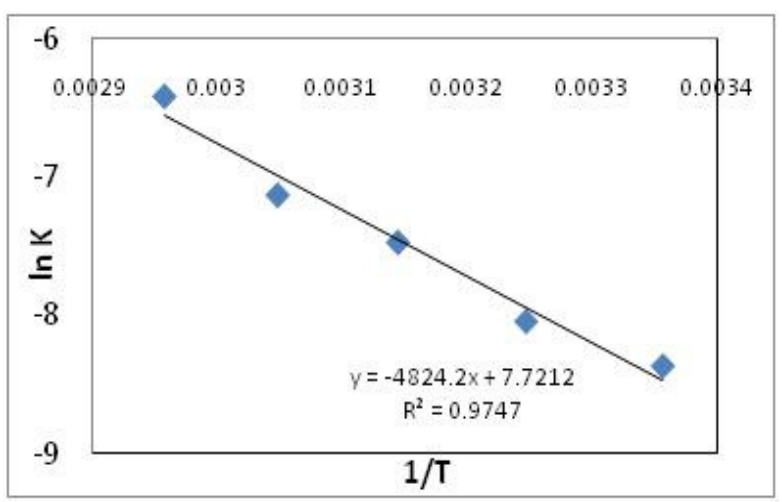

Fig. 7.Arrhenius plot using lactic acid at reaction conditions (Acid concentration $=10 \mathrm{wt} \%, \mathrm{~L} / \mathrm{S}=5$ $\mathrm{ml} / \mathrm{g})$.

\section{Conclusions}

1. In the end of leaching reaction, it was found that the final particles are hard, firm and unchanging in size. Therefore the shrinking core model (SCM) can be considered appropriately fit regarding this dissolution behavior.

2. From correlation coefficient values of the regression for the rate expressions it was found that the leaching was controlled by chemical reaction and value of reaction rate constant in return to this regression was $\left(2.51 \times 10^{-4} \mathrm{sec}^{-1}\right)$. This value indicate that the reaction rate is highly dependent on the initial concentration of reactant (lactic acid).

3. Regression analysis of the experimental data with Arrhenius equation fitted with correlation coefficient (0.9747) giving $40.108 \mathrm{KJ} / \mathrm{mole}$ for the activation energy $\left(E_{a}\right)$ and Arrhenius constant $\left(K_{o}\right)$ was $\left(2.256 \times 10^{3} \mathrm{sec}^{-1}\right)$. These results show that the reaction rate constant is highly affected by the temperature variation. In another words, increasing the temperature by $50^{\circ} \mathrm{C}$ cause an increase in the reaction rate constant value by 10 times.

\section{Acknowledgments}

The authors like to express high appreciation and thanks to the:

- Chemical Engineering Department, College of Engineering, University of Baghdad.

- Central Environmental Laboratory, College of Science, University of Baghdad.

- Construction National Center for Construction Laboratories and Research, Ministry of Construction and Housing.

For providing facilities to complete the chemical tests required by this research.

\section{References}

[1] Abouzeid, A.Z., 2008. "Physical and thermal treatment of phosphate ores-An overview". Int. J. Miner. Process. 85, pp. 59-84.

[2] Becker, P., 1983. "Phosphates and Phosphoric Acid: Fertilizer Science and Technology Series". Vol. 3, Marcel Dekker Inc., New York.

[3] Bilgic, S., 2002. "The inhibition effects of benzoic acid salicylic acid on the corrosion of steel in sulfuric acid medium". Materials Chemistry and Physics, 76, pp. 52-58.

[4] Cussler, E.L., 2007, "DIFFUSION, Mass Transfer in Fluid Systems", 3d Ed, Cambridge University Press, United Kingdom.

[5] Gharabaghi, M., Irannajad, M. and Noaparast, M., 2010. "A review of the beneficiation of 
calcareous phosphate ores using organic acid leaching", Hydrometallurgy, 103, pp. 96-107.

[6] Gharabaghi, M., Noaparast, M. and Irannajad, M., 2009. "Selective leaching kinetics of low grade calcareous phosphate ore in acetic acid", Hydrometallurgy, 95, pp. 341-345.

[7] Gremillion, L.R. \& McClellan, G.H. 1975. "Importance of chemical and mineralogical data in evaluating apatitic phosphate ores". Society of Mining Engineers of AIME. Transactions, 270.

[8] Guimarães, R.C., Araujo, A.C. and Peres, A.E.C., 2005. "Reagents in igneous phosphate ores flotation". Minerals Engineering, 18, pp. 199-204.

[9] Haweel, C. K., Basma, H., Abdulmajeed, A. and Eisa, M.Y. 2013, Beneficiation of Iraqi Akashat phosphate ore using organic acid leaching. Al- Khwarizmi Eng. J., 9(4): 2438

[10] Heidarpour, T., 2009. "Processing of Dalir phosphate samples using leaching method", M.Sc. Thesis, Department of Mining \& Metallurgical Engineering, Amirkabir University of Technology, Iran.

[11] Hem, S.R., 1993. "Kinetics of Metallurgical Reactions". Oxford and IBM Pub. Co., New Delhi.

[12] Kirk-Othmer, 1998. "Encyclopedia of Chemical Technology", 4th Ed, John Wiley \& Sons Inc., 18, pp.323.

[13] Kunii, D., and Levenspiel, O., 1991. "Fluidization Engineering, 2nd Ed", Butterworth, Boston, MA, USA.

[14] Malash, G.F., 2005. "Beneficiation of Abu Tartur phosphate rock by leaching with dilute acetic acid solution", Alexandria Engineering Journal, 44, 2, pp.339-345.

[15] Octave, L., 1999. "Chemical Reaction Engineering, 3d edition". John Wiley \& Sons, New York, USA.

[16] Ozer, A.K., 2003. "The characteristics of phosphate rock in a fluidized bed for the upgrading". Advanced Powder Technology, 14, 1, pp.33-42.

[17] Rao, T.C., Rao, L.S. and Rao, G.M., 1992. "Beneficiation of Indian low grade phosphate deposits: problems and prospects", Transactions of the Indian Institute of Metals, 45, 3, pp.195-205.

[18] Sluis, Van Der, 1987. "A Clean Technology Phosphoric Acid Process". Ph.D. thesis, Delft University Press, Netherlands.

[19] Straaten, P.V., 2002. "Rocks for Crops, Agro minerals of sub-Sahara Africa". Nairobi, Kenya, pp.7-24.

[20] Yagi, S., and Kunii, D., 1955, 5th Symposium (International) on Combustion, Reinhold, New York; Chem. Eng. (Japan), 19, 500, pp.231.

[21] Zafar, Z.I. and Ashraf, M., 2007. "Selective leaching kinetics of calcareous phosphate rock in lactic acid", Chemical Engineering Journal, 131, pp.41-48. 


\section{دراسة حركية استخلاص خام فوسفات عكاشات العراقي باستخدام حمض اللبنيك

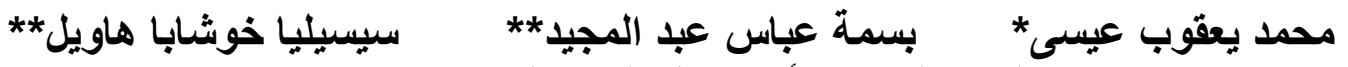

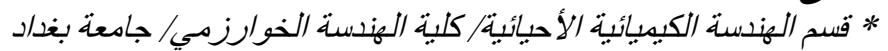

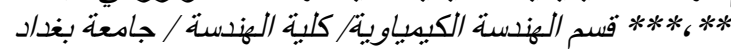 \\ *البريد الالكتروني: yahoo.com}

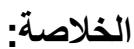

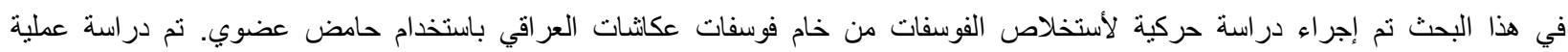

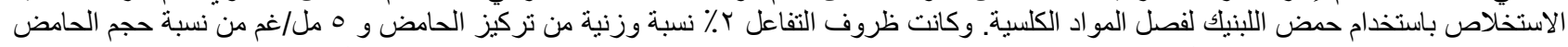

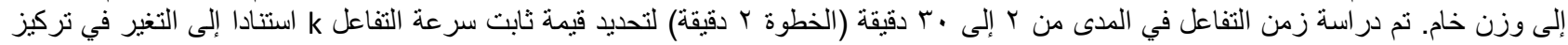

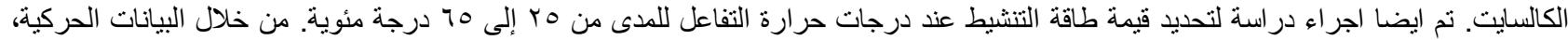

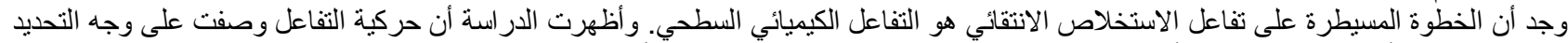

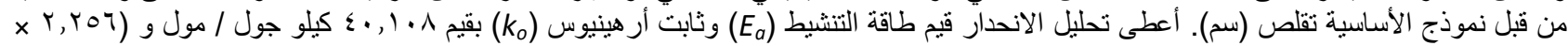
r • ( ثانية - (') على التو الي. 